\title{
A Study of Mobile User Movements Prediction Methods
}

\author{
J. Venkata Subramanian', S. Govindarajan ${ }^{2}$ \\ ${ }^{1}$ Department of Computer Applications, SRM Institute of Science \& Technology, India \\ ${ }^{2}$ Department of EDP, SRM Institute of Science \& Technology, India
}

\begin{tabular}{l}
\hline \hline Article Info \\
\hline Article history: \\
Received Oct 10, 2017 \\
Revised Feb 6, 2018 \\
Accepted Sep 14, 2018
\end{tabular}

\section{Keyword:}

Comparison

Data mining

Location prediction

Tracking

\begin{abstract}
For a decade and more, the Number of smart phone users count increasing day by day. With the drastic improvements in Communication technologies, the prediction of future movements of mobile users needs also have important role. Various sectors can gain from this prediction. Communication management, City Development planning, and locationbased services are some of the fields that can be made more valuable with movement prediction. In this paper, we propose a study of several Location Prediction Techniques in the following areas.
\end{abstract}

Copyright (C) 2018 Institute of Advanced Engineering and Science. All rights reserved.

\section{Corresponding Author:}

J.Venkata Subramanian,

Department of Computer Applications,

SRM Institute of Science \& Technology,

Kattankulathur - 603 203, Chennai, India.

Email: jvenkatmail@gmail.com

\section{INTRODUCTION}

In Personal Communication Systems, the wireless technologies were boomed about more than 10 years, To get the successful communication between humans, the usage of cellular phones are very much important. The mobile phone users always need various services from the service providers. Almost all service providers assuring the Quality Of Service to their customers in all around the world. In a coverage area of any service provider, thousands of users availing the communication services from the providers at a same time. To provide better quality of services to the customers, the companies, implements and follows various techniques for management of locations in their own coverage area and help to the government.

The coverage area, the entire geographical space has been divided into the hexagonal shaped cells. For example, a particular user can travel almost in a same route from his home to office every day. With this trajectory of user, the route has been recorded in the database in a period of time, and also the route involved cells and neighborhood cells also recorded. With these historical movements, we can predict the future movements also. So we can provide better quality of services to the users.

\section{COMPARISION} research areas.

In this paper, we have compared, several methods used by various authors in the following fields of

\subsection{Local Linear Regression Model}

The Authors [1] used Statistical method namely local linear regression model. They propose short memory adaptive location predictor having adaptation capability which has been achieved through fuzzy 
controller. The experiments conducted with real GPS data. The local regression model based on kernel weighted functions to determine user's future location using extrapolation.

\subsection{Location and Trajectory Information Model}

The another model used by authors [1] are, location and trajectory information model in which the location of user at time $\mathrm{t}$ can be represented by $2 \mathrm{D}$ vector, the exact position can be predicted. The Performance of Location Prediction assessed by real GPS values.

\subsection{Spatial Context Classifier and Short-term Predictor}

The authors [2] proposed an efficient spatial context classifier and a short-term predictor for the future location of a mobile user in mobile phone networks. In this paper, the authors adopted pattern namely classification in order to predict the future location of a mobile user based on the spatial context i.e.,

a. the current position and direction of the user,

b. the history of the trajectories followed by the user, and

c. the information on the user's surroundings (neighboring network cells).

The authors analyzed the previous Naïve basis classification and found the difficulties in handling semi random and fully random movement patterns. For classification, the following three types methods used.

a. Non Parametric trajectory classifier

b. Non metric trajectory classifier

c. Multi expert trajectory classifier

For location prediction, Macro cell based location predictor and Micro location predictor with their types were used. The Qualitative and quantitative assessments have done for performance evaluation. Simulations with synthetic and real-world mobility data shown that the proposed short-term Micro Direction based Location predictor got high prediction efficiency and accuracy, Therefore delivering LPs suitable for advanced context-aware applications.

\subsection{Movement Prediction Framework}

In this paper, the authors [3] mainly focused the location prediction during emergencies. The found the user's behaviors are changed in-case of emergency. A new movement prediction framework has been framed in Wireless LAN The users are aware of their locations using the GPS and velocities from the successive locations. Moreover, the users are also aware about the other users. For simulation, around 50 users movements were evaluated. The prediction accuracy level they achieved nearly 100\%.

\subsection{Cluster-based Temporal Mobile Sequential Pattern Mining}

The Algorithm used by Authors [4] is CTMSP-Mine along with Cluster object based smart cluster Affinity Search Technique and assessed with Location based Service Alignment. After Creating patterns, to predict the user behavior and recommending services. For simulation, the authors used Matlab. The following data processing methods also used they are pick mix, sampling, partitioning, field reordering etc., Get Number of time Segmenting Points Algorithm used to find the user behaviours in various time segments.

\subsection{Association Rules}

The Authors [5] selected the well known Association Rules from Data Mining to find the solutions for Mobility Prediction and Location Management. In Association Rules, the available hidden links between data, the prediction can be made excellent. They have taken a small coverage area (Ex.Waterloo) and separated into 45 hexagonal cells. Using the movements Simulator, the Predictions made. The Authors got around $90 \%$ of accuracy level.

\subsection{Genetic Algorithm and Ant Colony Optimization}

Using the above two algorithms[6], there are two different algorithms proposed to determine the total distance based on finding maximum flow in wireless networks and generate pheromone matrix of ants and estimate the content of the path using neighborhood that the user have not been visited in the particular networks. The authors were evaluated to optimize the location of controllers in wireless networks and compared with greedy algorithms.

\subsection{Clustering based Sequential Pattern Mining \& Sequential Pattern Mining based Clustering}

The authors [7], first analyses about Sequential Pattern Mining and Clustering techniques and their deficiencies. So, They proposed the following two algorithms namely. 


\subsection{Clustering based Sequential Pattern Mining}

This model aims to utilize the analogous movement characteristics of mobile users to deal with the deficiency of mobility behaviors of individuals. By using such similar mobility behaviors, the model may given the estimating future movement of a new user or historical user. This model has not discarded random movements from mobile users' histories before clustering mobility behaviors into similar groups. The authors generated a dataset with only 5 movement behaviors.

\subsection{Sequential Pattern Mining based Clustering}

This model mainly concentrated on eliminating noise of random movements in users' histories to improve the quality of generated groups of similar mobility behaviors. And also this model found the movement group to which the current trajectory belongs and then extracts all mobility rules from this group. The next location of the current trace is selected based on its best matching regulation. The authors concluded the combination of above models will give the accurate prediction of movements.

\subsection{Object Tracking Algorithm}

The Object Tracking Algorithm [8] found from the combination of Fuzzy logic and Neural Networks. Using Multi layer perceptron the proposed approach was evaluated in MatLAB environment. With the help of small dataset the predictions were made by authors. For handling the imprecision data, they used the concept of Fuzzy Logic. The Author achieved 80\% of Accuracy Level from the dynamic training of Special Neural Network.

\subsection{Multi Agent System for Movement Analysis}

The System was developed by the authors [9], to find out the location prediction in Mobile Networks. The authors used MIT Reality Mining Dataset with a sample of 10 selected participants. Movement Record Analysis taken for analyzing find out the stationary locations, i.e., the significant time staying in the significant places with probable locations of users. To estimate the location probabilities, the movement analysis and location prediction were needed.

The System works under the center point of the coordinator agent can able to manage the flow of required jobs and contact with other agents. There are two predictors are used by authors, if the movements are regular we need neural network based predictor. On the other hand, if irregular, we need probability based predictor. The accuracy obtains high , when probable location of 3 neighboring locations.

\subsection{Markov based Methods}

There are three methods were analyzed by authors [10]. They are Markov based methods, social Analysis based methods and Hybrid methods. In Markov based methods, The mobility history of users is collected both at inter-cell level with the help of cell id and also by using GPS at intra-cell level. With the help of Second order Markov Predictor for both spatial movements and temporal behavior, Prediction takes place. They show results around 76\% of accuracy when compared to GPS Positioning.

\subsection{Social Analysis based Methods}

In the Social Analysis based methods, will deliver a location prediction system in cloud. based on movement pattern discovery and analysis. They have merged the Location estimation and social information by analyzing the time between two users make a cell and the time they are located in the same cell. The result will be the format of table contains relevant locations sorted by the probability of visiting. The prediction was evaluated by the Dataset. Regarding the precision, listed out from $1^{\text {st }}$ hour to $6^{\text {th }}$ Hour.

\subsection{Hybrid Method}

The next Hybrid method, the prediction made as a Service for improve applications as mobility aware personalization and predictive resource allocation. These methods combines the early markov methods and collective behavioral patterns. The MPaaS Scheme evaluation proving with positively influence the markov based predictors. Here the authors were got only around 30\% of accuracy for the first 6 hours. Whereas the next 6 hours with high regularity the accuracy around $70 \%$. 
Table 1. Comparison Study of Various Mobile Prediction Methods

\begin{tabular}{|c|c|c|c|c|c|}
\hline Sl.No. & Authors and Year & $\begin{array}{c}\text { Approach / } \\
\text { Methods Used }\end{array}$ & $\begin{array}{l}\text { Training Dataset } \\
\text { Used }\end{array}$ & Area & $\begin{array}{c}\text { Environment } \\
\text { (Campus/Public) }\end{array}$ \\
\hline 1. & $\begin{array}{l}\text { Theodoros Anagnostopoulos, Christos } \\
\text { Anagnostopoulos } \\
\text { \& Stathes Hadjiefthymiades } 2010\end{array}$ & $\begin{array}{l}\text { Local linear } \\
\text { regression model } \\
\text { Location and } \\
\text { trajectory } \\
\text { information model }\end{array}$ & $\begin{array}{l}\text { With Real GPS } \\
\text { Traces }\end{array}$ & $\begin{array}{l}\text { Statistical and } \\
\text { Fuzzy Control }\end{array}$ & Public \\
\hline 2. & $\begin{array}{c}\text { Theodore Anagnostopoulos, Christos } \\
\text { Anagnostopoulos, \& Stathes } \\
\text { Hadjiefthymiades } 2012\end{array}$ & $\begin{array}{l}\text { Spatial context } \\
\text { classifier }\end{array}$ & $\begin{array}{l}\text { MIT Reality } \\
\text { Mining Dataset }\end{array}$ & $\begin{array}{c}\text { Pattern } \\
\text { Classification }\end{array}$ & $\begin{array}{l}\text { Public (Home to } \\
\text { Campus and } \\
\text { Campus to } \\
\text { Home) }\end{array}$ \\
\hline 3. & $\begin{array}{l}\text { Nusrat Ahmed Surobhi } \\
\text { \& } \\
\text { Abbas Jamalipour } 2012\end{array}$ & $\begin{array}{l}\text { Movement } \\
\text { Prediction } \\
\text { Framework }\end{array}$ & $\begin{array}{l}50 \text { Nos. of Mobile } \\
\text { users }\end{array}$ & $\begin{array}{c}\text { Network } \\
\text { Communication }\end{array}$ & $\begin{array}{l}\text { Indoor(WLAN } \\
\text { based Machine to } \\
\text { Machine } \\
\text { Network) }\end{array}$ \\
\hline 4. & $\begin{array}{l}\text { Sandhya Avasthi, Avinash Dwivedi } \\
2013\end{array}$ & $\begin{array}{c}\text { Cluster-Based } \\
\text { Temporal Mobile } \\
\text { Sequential Pattern } \\
\text { Mining }\end{array}$ & --- & Data Mining & --- \\
\hline 5. & $\begin{array}{l}\text { Rachida Aoudjit, Malika Belkadi, } \\
\text { Mehammed Daoui, Lynda Chamek, } \\
\text { Sofiane Hemrioui \& } \\
\text { Mustapha Lalam } 2013\end{array}$ & Association Rules & $\begin{array}{l}\text { A small no. of } \\
\text { users movements } \\
\text { were recorded by } \\
\text { simulator database }\end{array}$ & Data Mining & $\begin{array}{l}\text { Public ( A Small } \\
\text { Area of } \\
\text { Waterloo) }\end{array}$ \\
\hline 6. & Dac-Nhuong Le 2013 & $\begin{array}{c}\text { Genetic } \\
\text { Algorithm \& Ant } \\
\text { Colony } \\
\text { Optimization } \\
\text { Clustering based }\end{array}$ & $\begin{array}{l}10 \text { Nos. of } \\
\text { optimal location } \\
\text { of controller } \\
\text { problem Instances }\end{array}$ & $\begin{array}{l}\text { Wireless } \\
\text { Networks }\end{array}$ & -- \\
\hline 7. & $\begin{array}{l}\text { Thuy Van T. Duong } \\
\text { \& } \\
\text { Dinh Que Tran } 2015\end{array}$ & $\begin{array}{l}\text { Sequential Pattern } \\
\text { Mining } \\
\text { Sequential Pattern } \\
\text { Mining based } \\
\text { Clustering }\end{array}$ & $\begin{array}{l}5 \text { initialized } \\
\text { movement } \\
\text { behaviours }\end{array}$ & Data Mining & Public \\
\hline 8. & Jawdat Jamil Alshaer 2015 & $\begin{array}{l}\text { Object Tracking } \\
\text { Algorithm }\end{array}$ & $\begin{array}{l}70 \text { Randomly } \\
\text { sampled locations } \\
\text { created by author }\end{array}$ & $\begin{array}{l}\text { Fuzzy Logic } \\
\text { and Neural } \\
\text { Networks }\end{array}$ & Public \\
\hline 9. & $\begin{array}{l}\text { Marin Vukovic } \\
\qquad \& \\
\text { Dragan Jevtic }\end{array}$ & $\begin{array}{l}\text { Multi Agent } \\
\text { System for } \\
\text { Movement } \\
\text { Analysis }\end{array}$ & $\begin{array}{l}\text { MIT Reality } \\
\text { Mining Project }\end{array}$ & Neural Network & Public \\
\hline 10. & $\begin{array}{l}\text { Cristian L. Leca, Leontin Tută, } \\
\text { Ioan Nicolaescu } \\
\text { \& Cristian I. Rîncu } 2015\end{array}$ & $\begin{array}{l}\text { Markov based } \\
\text { methods } \\
\text { Social Analysis } \\
\text { based method } \\
\text { Hybrid method }\end{array}$ & $\begin{array}{l}\text { MIT Reality } \\
\text { Mining Project }\end{array}$ & $\begin{array}{l}\text { Statistical and } \\
\text { Networks }\end{array}$ & Public \\
\hline 11. & $\begin{array}{c}\text { Haitao Zhang, Zewei Chen, Zhao Liu, } \\
\text { Yunhong Zhu, \& } \\
\text { Chenxue Wu } 2016\end{array}$ & $\begin{array}{l}\text { Rough Prediction } \\
\text { and Accurate } \\
\text { Prediction }\end{array}$ & $\begin{array}{l}\text { KAnonymity } \\
\text { Dataset created } \\
\text { from Google } \\
\text { Maps, Foursquare, } \\
\text { BaiduMaps, etc }\end{array}$ & Data Mining & Public \\
\hline 12. & $\begin{array}{l}\text { Sungjun Lee, Junseok Lim, Jonghun } \\
\text { Park \& Kwanho Kim } 2016\end{array}$ & $\begin{array}{l}\text { Spatio-temporal } \\
\text { Periodic Pattern }\end{array}$ & $\begin{array}{l}714,448 \mathrm{WiFi} \\
\text { signal logs around } \\
50 \text { Days }\end{array}$ & Data Mining & $\begin{array}{l}\text { Campus of Seoul } \\
\text { National } \\
\text { University }\end{array}$ \\
\hline 13. & $\begin{array}{l}\text { Ahmed Azeez Khudhair, Saba Qasim } \\
\text { Jabbar, Mohammed Qasim } \\
\text { Sulttan } \\
\text { \& } \\
\text { Desheng Wang } \\
2016\end{array}$ & $\begin{array}{l}\text { triangulation, } \\
\text { fingerprinting, } \\
\text { proximity, vision } \\
\text { analysis and } \\
\text { trilateration }\end{array}$ & $\begin{array}{l}\text { Some Indoor } \\
\text { Localization } \\
\text { Systems }\end{array}$ & $\begin{array}{l}\text { Wireless } \\
\text { Systems }\end{array}$ & Indoor \\
\hline 14. & $\begin{array}{c}\text { V.Nivedha, } \\
\text { E. Karunakaran } \\
\text { \& J.Kumaran@Kumar } 2017\end{array}$ & $\begin{array}{c}\text { Approximate } \\
\text { Multiple } \\
\text { alignment pattern } \\
\text { mining }\end{array}$ & --- & Data Mining & Public WLANS \\
\hline 15. & $\begin{array}{c}\text { Sushil Kumar Verma, R.S. Thakur } \\
\text { \& Shailesh Jaloree } 2017\end{array}$ & $\begin{array}{l}\text { Fuzzy Association } \\
\text { Rule Mining }\end{array}$ & $\begin{array}{l}204 \text { Students } \\
\text { Records }\end{array}$ & Data Mining & $\begin{array}{c}\text { Samrat Ashok } \\
\text { Technological } \\
\text { Institute, Vidisha, } \\
\text { Madhya Pradesh, } \\
\text { India }\end{array}$ \\
\hline
\end{tabular}




\subsection{Rough Prediction and Accurate Prediction}

The basic theory of Location Based System queries and the primitives of Location Based System privacy were introduced. Samples of anonymity datasets adopted by a typical method of spatial-temporal k-anonymity were explained. For predicting the locations, the following steps were proposed by authors [11].

a. Extracting sequential rules from anonymity datasets

b. Building transition probability matrices from the mined sequential rules;

c. Normalizing the transition probabilities

d. Calculating n-step transition probability matrices

e. Crafting a rough prediction method and an accurate prediction method based on the n-step transition probability

The Predictions were evaluated by the two types of experiments, In the Exp.1, accurate prediction finds from the detailed paths obtained by using the Algorithm which gets inputs as simple paths of mobiles. Whereas in the Exp.2, verify the correctness of the proposed Location prediction methods.

\subsection{Spatio-temporal Periodic Pattern}

The above pattern [12] was used for capture the visits of the places of mobile users in different timings and different days, based on the past visits, the future visit will be predicted. The authors were experimented with real data set of the students of Seoul National University. The GPS and WIFI were acted as recorders of the user visits. And also smart phones involved. The experiments implemented by first order markov chain methods.

\subsection{Triangulation, fingerprinting, proximity, vision analysis and tri-lateration Techniques:}

The authors [13] measured the above five local prediction approaches, and estimated the performance in-terms of Accuracy, Robustness, Cost, Scalability and complexity. Their characteristics of indoor localization systems were listed. In the above study, the authors considered about the continuously tracking people between indoor and outdoor environments.

\subsection{Approximate Multiple Alignment Pattern Mining:}

The authors [14] combined Clustering and Sequential Pattern Mining techniques found the Approximate Multiple Alignment Pattern Mining technique that used quality rules and discovered from various similar user behaviors. The authors found Location Prediction based on individual Movement History and Multiple user movements histories.

\subsection{Fuzzy Association Rule Mining:}

By using the above method, the authors [15] were evaluated the performance of two sets of students and predicted the performance in end of the semester of their course based on the previous academic performance likely attendance, internal marks etc., and found the revision of curriculum and all.

\section{CONCLUSION}

In the above study, many authors used data mining techniques to find the locations of the movements of the mobile users. But, the Data Mining techniques having two drawbacks, the first is, they may fail to predict new users or users with movement on novel methods. Second, reduction in accuracy for regular movement and random movements having similar quality behaviors of mobile users. To overcome this situation, Researchers can choose Neural Networks for getting accuracy and exact prediction of Locations.

\section{REFERENCES}

[1] Theodoros Anagnostopoulos, Christos Anagnostopoulos \& Stathes Hadjiefthymiades, An adaptive location prediction model based on fuzzy control, Computer Communications,Elsevier (2010),Vol 34, pp.814-834.

[2] Theodoros Anagnostopoulos, Christos Anagnostopoulos \& Stathes Hadjiefthymiades, Efficient Location Prediction in Mobile Cellular Networks, International Journal of Wireless Information Networks, Springer (2012), Vol-19, pp.97-111.

[3] Nusrat Ahmed Surobhi \& Abbas Jamalipour, Movement Prediction of Mobile Users inEmergencies Using M2M Networks, IEEE 23rd International Symposium on Personal, Indoor and Mobile Radio Communications, (2012)pp.2535-2540.

[4] Sandhya Avasthi, Avinash Dwivedi, Prediction of Mobile user Behavior using Clustering, International Journal of Scientific and Research Publications,(2013), Vol. 3, Issue 2, pp.1 - 5. 
[5] Rachida Aoudjit, Malika Belkadi, Mehammed Daoui, Lynda Chamek,Sofiane Hemrioui \& Mustapha Lalam, Mobility Prediction Based on Data mining, International Journal of Database Theory and Application, (2013), Vol. 6, No. 2, pp.71-78.

[6] Dac-Nhuong Le, (2013), GA and ACO Algorithms Applied to Optimizing Location of Controllers in Wireless Networks, International Journal of Electrical and Computer Engineering, Vol. 3, No. 2, pp. 221 229

[7] Thuy Van T. Duong \& Dinh Que Tran, A Fusion Of Data Mining Techniques For Predicting Movement Of Mobile Users, Journal of Communications and Networks,(2015), VOL. X, NO. Y, pp.1-14.

[8] Jawdat Jamil Alshaer, Mobile Object-Tracking Approach using a Combination of Fuzzy Logic and Neural Networks, Global Journal of Computer Science and Technology ( E ), (2015), Vol. XV Issue VIII Ver. I Year, pp.19-25.

[9] Marin Vukovic \& Dragan Jevtic, Agent-based Movement Analysis and Location Prediction in Cellular Networks, 19th International Conference on Knowledge Based and Intelligent Information and Engineering Systems(Elsevier), (2015),pp. 517 - 526 .

[10] Cristian L. Leca, Leontin Tută, Ioan Nicolaescu \& Cristian I. Rîncu, Recent advances in location prediction methods for cellular communication networks, IEEE $23^{\text {rd }}$ Telecommunications forum(2015), pp.1-5.

[11] Haitao Zhang, Zewei Chen, Zhao Liu, Yunhong Zhu, \& Chenxue Wu, Location Prediction Based on Transition Probability Matrices Constructing from Sequential Rules for Spatial-Temporal KAnonymity Dataset, PLOS ONE Journal, (2016), pp. 1 - 22.

[12] Sungjun Lee, Junseok Lim, Jonghun Park \& Kwanho Kim, Next Place Prediction Based on Spatiotemporal Pattern Mining of Mobile Device Logs, MDPI (Sensors) Journal,(2016), pp.1-19.

[13] Ahmed Azeez Khudhair, Saba Qasim Jabbar, Mohammed Qasim Sulttan, Desheng Wang, Wireless Indoor Localization Systems and Techniques: Survey and Comparative Study, Indonesian Journal of Electrical Engineering and Computer Science, (2016), Vol. 3, No. 2, pp. $392 \sim 409$

[14] V.Nivedha, E. Karunakaran \& J.Kumaran@Kumar, A Novel Approach for Predicting Movement of Mobile Users Based on Data Mining Techniques, International Research Journal of Engineering and Technology, (2017), Vol-4, Issue - 4, pp 3603 - 3608 .

[15] Sushil Kumar Verma, R.S. Thakur, Shailesh Jaloree, Fuzzy Association Rule Mining based Model to Predict Students' Performance, International Journal of Electrical and Computer Engineering, (2017), Vol. 7, No. 4, pp. 2223 2231. 